\title{
LA UNIVERSIDAD DE LAS COMPETENCIAS: EL LUGAR DEL CONOCIMIENTO EN EL CAPITALISMO CONTEMPORÁNEO*
}

\begin{abstract}
Resumen
Las reformas educativas que actualmente se adelantan no provienen necesariamente de grandes paquetes legislativos. Se están produciendo cambios en las instituciones educativas jalonados más por las exigencias que se les hacen a los estudiantes por medio de las pruebas estandarizadas del nivel nacional e internacional. En esas pruebas ya nos se les exigen conocimientos concretos, sino manejo de competencias. Tienen que ser competentes (actuar en contexto) para obtener el pase que los habilita a seguir estudiando o desempeñarse en el mundo laboral. Este artículo trata de los problemas que estas prácticas le plantean a la universidad, en particular, y a la escuela, en general. Muestra lo que ha pasado con el modo de producción capitalista y el impacto que su transformación ha producido en el conocimiento y viceversa. Plantea los retos que de allí se derivan para que los profesores puedan seguir incidiendo en sus destinos, con algún grado de autonomía, para rescatar el espíritu que occidente había prometido cuando propuso pensar más allá de lo obvio y trascender las exigencias de la sociedad misma.
\end{abstract}

Palabras clave: Conocimiento, universidad, competencias, capitalismo, pedagogia.

\section{A UNIVERSIDADE DAS COMPETÊNCIAS: O LUGAR DO CONHECIMENTO NEL CAPITALISMO CONTEMPORÂNEO}

\begin{abstract}
Resumo
As reformas educativas que na atualidade adiantam-se não provem necessariamente dos grandes paquetes legislativos. Os câmbios produzidos no interior da instituição educativa são puxados pelas exigências que se fazem aos estudantes nas provas estandarizadas do nível nacional e internacional. Nestas provas não se fazem demandas de conhecimentos concretos, más sim o saber das competências. Os estudantes devem ser competentes (atuar em contexto) para obter o passe que os habilita a seguir estudando e a possibilidade de um trabalho. Neste artigo tratase dos problemas que as práticas evaluativas planeiam á universidade em particular e a escola em geral. O modo produção capitalista e o impacto que ditos câmbios produz em o conhecimento e vice versa. Sinala os retos derivados para que os professores possam seguir incidindo nos seus destinos, com algum grado de autonomia, resgatando o espírito que ocidente planejo ao propor pensar além do obvio e transcender as exigências da sociedade mesma.
\end{abstract}

Palabras chaves: Conhcimento, universidade, competências, capitalismo, pedagogía.

Profesor titular de la Universidad Pedagógica Nacional. Doctor en Filosofía y Ciencias de la Educación.

Correo electrónico: rizoma.alejandro@gmail.com

** Este artículo ha sido escrito en el marco de la investigación "Paradigmas y conceptos de la pedagogía en Colombia" que el autor adelanta con el Grupo de Historia de la Práctica Pedagógica del cual es miembro, financiado por Colciencias.

Artículo recibido el 1 de marzo de 2009 y aprobado el 12 de junio de 2009.

Pedagogía y Saberes N. 28. Universidad Pedagógica Nacional. Facultad de Educación, 2008, pp. 71-80 


\title{
THE UNIVERSITY OF COMPETENCES: THE PLACE OF THE KNOWLEDGE IN CONTEMPORARY CAPITALISM
}

\begin{abstract}
The educational reforms that are taking place at the present moment do not come from huge legislative actions. The changes are being undertaken from the core of the educational institutions and are motivated by the increasing challenges of the national and international standardized tests that students are taking. In these tests, they have to show handling of competences, not specific knowledge. They have to be competent -act within the context- to move to the next level: continue with their studies or perform successfully in the job market.

This article explains the problems that the higher education(in particular) and the school system (in general) are having because of these practices. It shows how the capitalist ways of production impact and transform today's knowledge (and vice versa). And how these changes are causing greater challenges for teachers in their hope to continue their influence on the student's destinies — while keeping some degree of autonomy — and saving the east's will: to go beyond the obvious and to transcend society's demands
\end{abstract}

Key words: Knowledge, university, competences, capitalism, pedagogy.

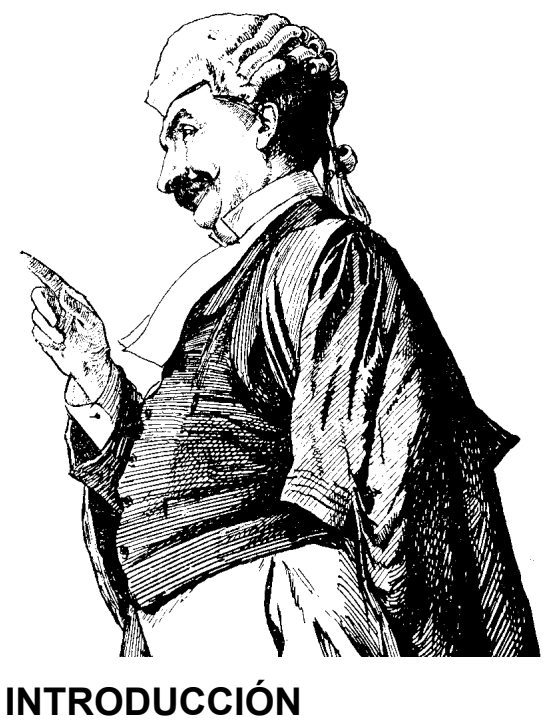

Para entender la universidad de hoy e interrogarnos como docentes responsables de la formación de los futuros profesionales, es necesario hacernos una pregunta sobre el lugar del conocimiento en las sociedades contemporáneas. Esto si aceptamos que la tarea central de la universidad es tratar con el conocimiento, en relación con las profesiones y con las personas que aspiran desempeñarse en un trabajo más o menos especializado en el mundo laboral.

La universidad es un acontecimiento histórico que se remonta a los inicios de la edad moderna (algunos historiadores -Bonvecchio, 1991 y Frey, 1991- plantean que las primeras universidades surgieron en el siglo XII y XIII, en la baja Edad Media europea). En la actualidad, se conservan muy pocos rasgos de aquello que le caracterizaba en las sociedades del capitalismo temprano. Pero si algo queda de ese pasado remoto es la idea de que en ella se forma la inteligencia, la cual, en el sentido moderno, está separada de otras prácticas de saber propias de la moral y la religión. Se trata de una inteligencia que actuaría racionalmente, según los postulados modernos. No es posible entonces entender la historia de la universidad sin la historia de las maneras de saber que, por lo menos en occidente, han existido de muy variadas formas. El conocimiento en sus múltiples manifestaciones atraviesa el centro de la historia de la universidad occidental. Su devenir, sus crisis, sus alteraciones, sus desdoblamientos, sus fracturas, sus mutaciones, en fin, sus múltiples formas de existencia son inseparables de la vida de la universidad. El destino de la universidad, desde su creación hasta ahora, estaría pues ligado al destino del conocimiento, en todas sus formas, en todas sus expresiones.

De manera que, para entender nuestro papel hoy como docentes universitarios, para responder a las preguntas acerca de lo que hay que saber hoy, lo que hay que enseñar, lo que es necesario investigar en función de la formación de personas interesadas en desempeñarse laboralmente en un campo especializado (¿profesionales?), para acercarse a estos interrogantes, es necesario discutir, en primer lugar, acerca de las formas de existencia contemporáneas de la ciencia, el conocimiento y el saber. De este asunto se ha ocupado la epistemología, pero desde que los historiadores sociales de la ciencia pusieron en duda la idea del progreso del conocimiento, el debate se ha complejizado, en particular en relación con las posturas posmodernas ${ }^{1}$. En segundo lugar, hay que analizar las tendencias que, en medio del devenir actual del conocimiento, se están moviendo en las reformas y, en general, de las políticas en educación

1 La bibliografía sobre las historias sociales de la ciencia es muy amplia, en principio habría que destacar a Bachelard (1948) desde una perspectiva psicoanalítica, a Koyré (1977) desde la historiografía, a Khun (1962) con el concepto de paradigmas, a Balibar (1977), quien pone en evidencia las continuidades entre Bachelard y Althusser, y a Foucault (1970) con su propuesta de arqueología del saber. La postura posmoderna que de alguna manera recogió todo el debate fue planteada por Lyotard (1987). 
superior hoy en el mundo. Allí se verá qué tanto las políticas recogen el debate académico y responden a una dinámica más económica, social o cultural. $\mathrm{Y}$, finalmente, considero importante hacer anotaciones acerca del papel de la pedagogía en la construcción de los saberes que consideramos legítimos enseñar hoy en nuestras universidades. Esto suponiendo que la manera en que nos enfrentamos cotidianamente en la docencia con el conocimiento forma parte de su proceso de transformación $\mathrm{y}$, por tanto, la pedagogía tiene mucho que decir al respecto.

Antes de abordar estos tres puntos, resulta fundamental explicitar mi postura sobre lo que está pasando hoy en día con la universidad colombiana2. Considero que la función pública de la universidad está francamente amenazada, así como su autonomía y sus posibilidades de ejercer una tarea inteligentemente crítica y comprometida con los más sensibles asuntos de la vida en sociedad. Esta crisis, a diferencia de las muchas otras que ha vivido (entendiendo que su existencia ha estado ligada a los conflictos que le son inherentes a la sociedad moderna), está poniendo en entredicho las posibilidades de potenciar aquello que le pertenece en su fuero más interno: su capacidad de tomar distancia del presente para interrogarlo y transformarlo.

La universidad, más allá de las múltiples tareas que ha tenido que cumplir para satisfacer todo tipo de demandas culturales, sociales, políticas y económicas, es el lugar por excelencia donde se puede pensar distinto y deliberar en medio de posiciones contradictorias. Si le quitáramos las funciones de solucionar problemas sociales y de formar profesionales funcionales a las demandas del mercado, tareas que por lo general la agobian y la sobrecargan y pueden realizar otro tipo de instituciones, lo que realmente quedaría como especificidad

2 Para ubicar la problemática de la universidad pública en el contexto latinoamericano Cfr. Organización de Estados Iberoamericanos (OEI) (1999) y Universia (2005). y como tarea indelegable sería la construcción de lugares para pensar distinto, para cambiar la mirada, para dudar, para sospechar de lo obvio, o de lo que de manera hegemónica se vuelve mayoritario. Esto como resultado precisamente del encuentro de muy diversas miradas del mundo. La universidad, en última instancia, no sería más que aquel resquicio minoritario que ha permanecido en el mundo occidental ejerciendo la disidencia, por tanto, lo que se puede esperar de ella es que allí no se diga la última palabra, como si todo estuviera dicho, como si todo estuviera consumado; al contrario, sería el lugar donde puede nacer lo nuevo, lo inesperado, lo intempestivo, más allá de toda evidencia, más allá de toda fuerza, incluida la fuerza de los hechos y de las balas. Por más contundentes y mayoritarias que puedan ser las acciones de fuerza que predominan en nuestras sociedades, las universidades, hasta ahora, han sobrevivido casi como trincheras a las más diversas formas de presión e intimidación.

Personalmente no creo en las visiones apocalípticas que anuncian el final de los tiempos cada vez que se quiere defender una posición que está siendo debilitada políticamente. No creo que la universidad vaya a desaparecer en el futuro inmediato. Pero como docentes nos corresponde tomar posturas éticas, políticas y académicas frente a aquellos hechos que vemos como amenazantes para lo que consideramos sustantivo de la tarea universitaria; repito: la posibilidad de pensar distinto y deliberar en medio de posturas contradictorias.

En Colombia, está haciendo carrera una idea absolutamente pragmática y funcional acerca del papel que la universidad cumple en la sociedad. En muy pocas palabras, lo que hoy orienta las políticas en educación superior son cuatro propósitos que, a mi juicio, son bastante simplificadores de los debates que deberían tenerse en cuenta a la hora de formular las políticas; el riesgo de reducir las políticas a estos cuatro propósitos es que son contundentemente eficaces y en la práctica la pueden transformar a nivel estructural. La universidad debe:
- Ampliar sus ofertas de educación técnica y tecnológica.

- Ampliar su cobertura por medio de las herramientas informáticas.

- Flexibilizar su oferta mediante el sistema de créditos.

- Reordenar sus currículos en función de los estándares con los que se evaluarán los estudiantes de último semestre de cada carrera; evaluación que sería requisito para el grado, según lo establecido con la instauración del Ecaes (Díaz et al., 2006).

Los recursos destinados en el último Plan de Desarrollo (2006-2010) ${ }^{3}$ para el fomento de la educación superior se invertirán exclusivamente allí. No hay una política financiada sobre la investigación, ni sobre las profesiones, ni sobre el conocimiento, ni sobre el profesorado.

Si los cuatro propósitos que orientan la actual política se sostienen en el tiempo y no se atienden los otros asuntos, en pocos años la institución universitaria habrá cambiado su naturaleza y será funcional a las nuevas exigencias del capitalismo posindustrial ${ }^{4}$. Esta es la hipótesis que quiero desarrollar a continuación. Para eso hay que acercarse a preguntas como ¿cuáles son esas exigencias? ¿Qué es lo que pasa hoy con el conocimiento en el capitalismo posfordista y en la sociedad posmoderna? ¿Qué pasa con las profesiones? ¿Qué pasa con el Estado y las fuentes de financiación? Para aproximarnos a estas preguntas y comprender algunas de las tendencias que orientan los principios de la política universitaria y las posibilidades que hoy tiene la universidad, en relación con el conocimiento y la pedagogía, quisiera apoyarme en varios

3 El documento se puede consultar en línea, disponible en: http://www.dnp.gov. co/PortalWeb/

4 Para tener una mirada histórica del proceso de institucionalización de la universidad colombiana en el contexto del capitalismo industrial, ver Lucio y Serrano (1992) 


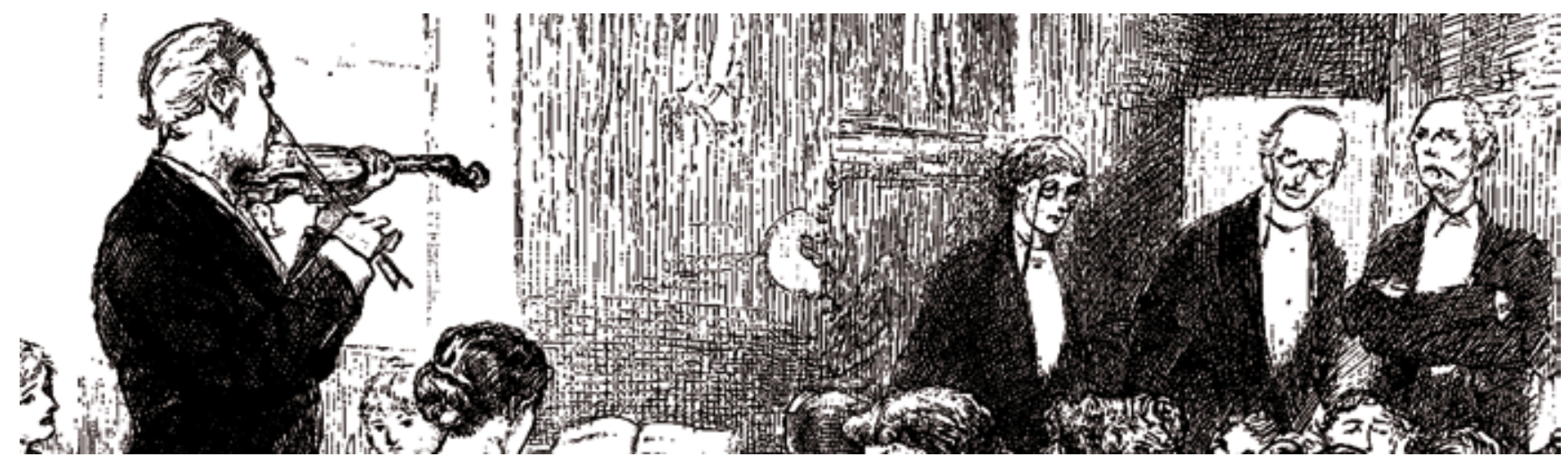

autores y hacer una síntesis crítica de un debate que es, por supuesto, mucho más complejo y abarca muchísimos más aspectos. Para analizar tan difícil asunto seguiré algunos de los planteamientos que han hecho al respecto Jean Francois Lyotard (1987), Paolo Virno (2003) y Zigmunt Bauman (2007).

\section{SOBRE EL MODO DE SER DEL CONOCIMIENTO EN LA CONTEMPORANEIDAD}

\section{El conocimiento como factor de producción}

Siguiendo a Jean Francois Lyotard en su trabajo La condición posmoderna (1987), vamos a plantear que en nuestra época el saber ha cambiado su naturaleza. Esto aceptando que no hay ya naturalezas estables, únicas o definitivas y que el mundo es significado de múltiples maneras en momentos históricos distintos, incluyendo a los seres humanos.

Para esta corriente filosófica, y en general para los analistas sociales que la siguen, después de la segunda guerra mundial la sociedad cambió sustancialmente. Nuestra época sería otra, y desde entonces estaríamos viviendo la emergencia y consolidación de un mundo que nunca antes había existido. Si esto es así, debemos saber qué fue lo que cambió, qué dejamos de ser y qué comenzamos a ser desde entonces. Para abordar estas preguntas, hay que aceptar entonces que no hay una naturaleza en el conocimiento y que su forma ciencia no existió siempre; por tanto, es susceptible de desaparecer.

Desde estas premisas se plantea entonces que el conocimiento llamado científico es resultado de una construcción histórica y, en ese sentido, es un discurso. Lyotard nos muestra la manera en que su forma discursiva adquiere hoy una especial relevancia, dado que el conocimiento de punta está basado en el lenguaje. Su ejemplo es la genética, que sería una ciencia nueva cuya lógica estaría fundamentada en un lenguaje también nuevo, el de la cibernética. Lo que hoy regula los conocimientos de frontera, los cuales están generalizando un modo de proceder en la investigación, son fundamentalmente lenguajes. Pero este no sería un indicador de los cambios sustantivos que ha sufrido el modo de conocimiento, si se acepta que la ciencia siempre ha sido un discurso. Lo que cambió fue la manera en que se legitiman a sí mismos dichos lenguajes. Según Lyotard, el conocimientos pasó de ser legitimado por un metadiscurso, que sería la Lógica Formal, a un principio que en la actualidad se conoce como performatividad, en el que lo único que importa es que las reglas de juego acordadas para validar un discurso se cumplan, renunciando a la existencia de un criterio único y universal de legitimación; su veracidad ya no estaría tampoco ligada a la comprobación empírico-sensorial, sino que dependería de la posibilidad de utilizar o no las técnicas que pudieran aislar la realidad en un laboratorio, y esto depende progresivamente del capital suficiente para acceder a los cada vez más sofisticados dispositivos electrónicos digitalizados.
El otro cambio sustantivo tuvo que ver con el sistema de administración de las pruebas que le daban validez científica a un conocimiento. Es el momento en el que se hace referencia a la realidad. El problema que se debía resolver allí era cómo probar la prueba, para que fuera creíble, para que tuviera validez. Para ello, un científico debía decir cuáles habían sido los medios que había utilizado para la prueba, de tal manera que cualquier otro científico pudiera validarla, esto es, realizarla y verificar los resultados. Pero las pruebas se constataban por medio de los sentidos, lo cual comenzó a generar problemas, pues se encontró que los sentidos eran limitados; por su alcance y por la capacidad de discriminación, eran relativos.

Por esa razón hubo que recurrir a las técnicas. En principio, las técnicas eran prótesis de los órganos de los sentidos, o de los sistemas fisiológicos humanos, hechas para ampliar la capacidad de recibir datos y actuar sobre los contextos; se buscaba optimizar las actuaciones en la administración de la prueba. Las técnicas ayudaban a disminuir la energía gastada al mismo tiempo que se ampliaba el volumen de información captada y de actuaciones sobre el contexto. Allí no importaba si la actuación del aparato era bella, justa o verdadera, lo que importaba era su eficiencia. Una actuación allí sería buena cuando ampliara capacidades o gastara menos que otra.

Durante mucho tiempo, la invención de las técnicas no interfería en la producción del saber; las técnicas se justificaban por sí mismas, pues no tenían como propósito producir saber. La técnica 
era un asunto de los artesanos y de los artistas y no buscaba soportar la argumentación científica, sino simplemente facilitar su búsqueda.

Pero cuando la pragmática del saber científico reemplazó los saberes tradicionales o revelados, las técnicas fueron usadas como medio para administrar las pruebas. Para poder construir esos laboratorios, que optimizaran las actuaciones del cuerpo humano, para poder desarrollar las técnicas de las cuales iba a depender la validez de las pruebas, se necesitaba un excedente en el gasto. No había entonces pruebas, ni verificación de enunciados, ni verdad, en últimas, sin dinero. Así, los juegos del lenguaje serían juegos ricos, y quien más rico fuera estaría en mejores condiciones de tener la razón. Se establece así una nueva ecuación en la ciencia: riquezaeficiencia-verdad.

No había entonces técnica sin riqueza, pero lo que se descubrió desde finales del siglo XVIII fue que tampoco habría riqueza sin técnica. Para desarrollar una técnica, se requería una inversión, pero se descubrió que las técnicas, al optimizar las actuaciones a las que se aplicaba, aumentaban la plusvalía, siempre y cuando el producto de esas actuaciones se vendiera. Con ese aumento de la plusvalía se podría competir mejor, pues parte de ella se reinvertiría en el mejoramiento de las técnicas para hacer más eficientes las actuaciones. Allí fue cuando la ciencia se convirtió en una fuerza de producción. La ciencia pasó a ser un momento en la circulación del capital. Esto fue así, por lo menos desde comienzos del siglo $\mathrm{XX}$, cuando cambió el papel de las técnicas en la producción del conocimiento llamado científico. Después, el asunto volvió a transformarse de nuevo radicalmente, como se verá.

Durante todo ese tiempo, la mejora de las técnicas y sus resultados importaba por las posibilidades de producir mercancías para la venta y de enriquecerse por medio de ellas, el saber dejó de ser un objetivo en sí mismo. Las técnicas estuvieron desde entonces más ligadas a la ganancia que a la ciencia misma.
Era el principio de performatividad (la eficiencia planteada en la relación inputoutput) el que orientaría esta dinámica.

Los principios preformativos de los centros de producción de técnicas permearon las instituciones académicas y los centros de producción de saber, como las universidades. Allí comenzó a prevalecer la idea de producir programas vendibles, y de producir para conseguir clientes. Donde no funcionara eso, habría menos recursos. Sobre esto volveremos más adelante.

Los capitalistas, desde entonces, son los que fomentan la ciencia. Ellos no compran sabios, técnicas y aparatos para saber la verdad, sino para aumentar su riqueza. $Y$ aumentan la riqueza para aumentar el poder. Por eso, el poder se convirtió en un criterio que intervendría en las formas de legitimación de la verdad.

En la modernidad, según Lyotard, habría tres tipos de juegos del lenguaje: el de la fuerza, el del derecho y el de la sabiduría. En ellos se distinguen tres propósitos distintos, la búsqueda de la fuerza, de la justicia o de la verdad. El juego denotativo del lenguaje, que sería el de la ciencia, sería pertinente en la relación verdadero-falso; el juego prescriptivo, el lenguaje del derecho, sería pertinente en la relación justo-injusto; el juego técnico, que sería el lenguaje de la fuerza, sería pertinente en la relación eficiente-ineficiente (Lyotard excluye de este juego de la fuerza al terror, porque allí no habría juego, simplemente se eliminaría al contrario, física o simbólicamente. De esa manera, se rompería el lazo social, no habría sociedad posible).

Lo que constituye hoy a la sociedad posindustrial, según Lyotard, es la expansión del principio de la fuerza, en la medida en que la performatividad controla hoy todas las formas de pruebas. La razón estará así cada vez más del lado de la técnica. A más técnica, mas posibilidades de tener razón, hasta que se convirtió en un modo de vida. El criterio técnico se extendió a toda la sociedad e invadió todas las formas de producción de conocimiento. De esta manera, la relación de la ciencia y la técnica se invirtió. El criterio de performatividad es el que importa a la hora de decidir en qué tipo de investigaciones se invierte.

¿Cómo sucedió esto? Al desarrollar las técnicas, una capacidad mayor de suministrar pruebas sobre la realidad se apoderó de ellas. De las técnicas provendría la posibilidad de legitimar la verdad y de formular prescripciones, a partir de lo cual se juzgaría lo justo y lo injusto y se tomarían las decisiones. Incluso el poder se comenzó a legitimar por la eficacia de sus actuaciones. En la medida en que se tuviera mayores posibilidades de controlar la realidad y de obtener más información sobre ella, se haría más efectiva la toma de decisiones, se actuaría con mayor certeza. Ahora, el incremento del poder y su autolegitimación dependería de la producción, memorización, accesibilidad y operacionabilidad de las informaciones.

De esta manera, el saber tendría sentido en tanto se pudiera vender y en el proceso de compra adquiriera un valor. En el proceso de cambio encontraría su realización, como cualquier mercancía. Como cualquier otro bien, el saber en estas nuevas condiciones habría perdido su valor de uso, pues ya no tendría sentido en sí mismo, ya no sería un fin en sí mismo, sino en cuanto produjera riqueza.

Tal como lo proclaman los economistas neoclásicos, el conocimiento se convirtió así en la principal fuerza de producción. Ya Marx lo había anticipado en los Grundrisse, cuando habló del intelecto general (general intellect), entendido como el conocimiento objetivado en las máquinas, como cuerpo social. En el proceso de desarrollo capitalista, este fenómeno ha ido transformando radicalmente la fuerza laboral (menos obreros de la industria manufacturera y más técnicos profesionales manejando máquinas). Por eso se creyó, por lo menos desde la década del treinta del siglo $\mathrm{XX}$, que la ciencia determinaba los niveles de desarrollo económico de un país.

El saber se volvió también determinante en la competencia mundial por el poder. 
Dominar la información sería desde entonces el objetivo en la lucha por el control del poder (recuérdese la Guerra Fría). Las estrategias industriales y comerciales y las militares y políticas estarían cada vez más relacionadas. En la medida en que la información se necesitara más para controlar el poder, debería ser más asequible y más fácil de decodificar. En ese sentido, el EstadoNación, que era el gran cerebro que regulaba la producción y circulación del conocimiento, se volvió un obstáculo que debía ceder el paso a los operadores privados. Llegó un momento en el que el Estado opacaba la necesidad de la transparencia de las comunicaciones, esto es, la comercialización de los saberes. Así, las relaciones entre economía y Estado cambiaron. Las decisiones más importantes sobre la inversión económica dejaron de ser un asunto del Estado-Nación. Este último ya no conduce, no protege, no planifica las inversiones. Las empresas dueñas de los satélites comunicacionales y de bancos de datos que habitan la órbita geoestacionaria son las que saben. En últimas, ellas dicen qué datos circulan y cuáles no. Allí hay un problema que ha transformado el Derecho clásico, pues el Estado se convirtió en un usuario más de esa información. Las relaciones con la sociedad civil también se afectaron y el mercado se hizo mundial.

En la medida en que las nuevas tecnologías son las que controlan los datos que se necesitan para la toma de decisiones políticas y económicas, lo medios de control son más móviles, y esto las hace a la vez más frágiles (están sujetas a la piratería, y se pueden imitar más fácilmente, como en efecto sucedió con la estrategia de productividad que implementaron en el sureste asiático y en Japón).

Los conocimientos fueron puestos en el mercado para cumplir el mismo papel de la moneda. Por esa razón tienen dos tipos de uso, como medio de pago o como medio de inversión. En el primer caso, el conocimiento se intercambia para reproducir la fuerza de trabajo; en el segundo, se intercambia para optimi- zar el funcionamiento de los medios de producción mismos. Allí, como inversión, el conocimiento sirve para decidir; como medio de pago, el conocimiento sirve para adquirir. Unos conocimientos sólo estarán a disposición de los que deciden, otros serán útiles para consumir. El hecho de que los conocimientos ya no importen per se, sino como medio, va a repercutir en la pedagogía. La relación que se plantea entre el conocimiento científico y la pedagogía cambió cuando el primero dejó de ser importante para formar al ser humano que desde el Renacimiento, pasando por la llustración, se había propuesto. Sobre esto se volverá más adelante. De esa manera, según Lyotard, se ha roto el lazo social que había constituido a la modernidad. En ese sentido, hablaríamos hoy de la condición posmoderna.

\section{El conocimiento como modo de ser del trabajo contemporáneo}

En la misma dirección que venimos planteando ha escrito Paolo Virno (2003), agregando una novedad que en los años setenta Lyotard no alcanzó a ver. Para este autor, el proceso productivo tiene hoy como materia prima el saber, la información, la cultura y las relaciones sociales $^{5}$. Esto cambia radicalmente el modo de entender el problema. Según el autor, hoy no es posible leer las formas de vida contemporáneas del capitalismo posfordista sino desde la filosofía y las teorías del lenguaje. Aunque los teóricos que han desarrollado la filosofía del lenguaje (Saussure, Wittgenstien) no se hubieran interesado por los procesos de producción, hoy son necesarios para entender la economía, veamos por qué.

Con Lyotard, se desarrolló la tesis que ya habían formulado los teóricos de la Escuela de Frankfurt, cuando señalaban que las técnicas y sus lógicas performativas habían copado todos los espacios sociales y habían "deshumanizado"

5 Tal proceso productivo se ha dado en llamar posfordismo. En él, ya no importa la división del trabajo y el control milimétrico de los movimientos, los espacios y la disciplina, como se había generalizado el modelo instalado por la Ford y con el cual se ganaba en eficiencia por el aumento en el volumen de la producción. En el posfordismo o toyotismo (esta vez fue la Toyota la que generalizó el modelo), lo que importa es la creatividad, la imaginación y la flexibilidad del proceso productivo. Se es competitivo no por volumen, sino por la originalidad en las mercancías que se producen.

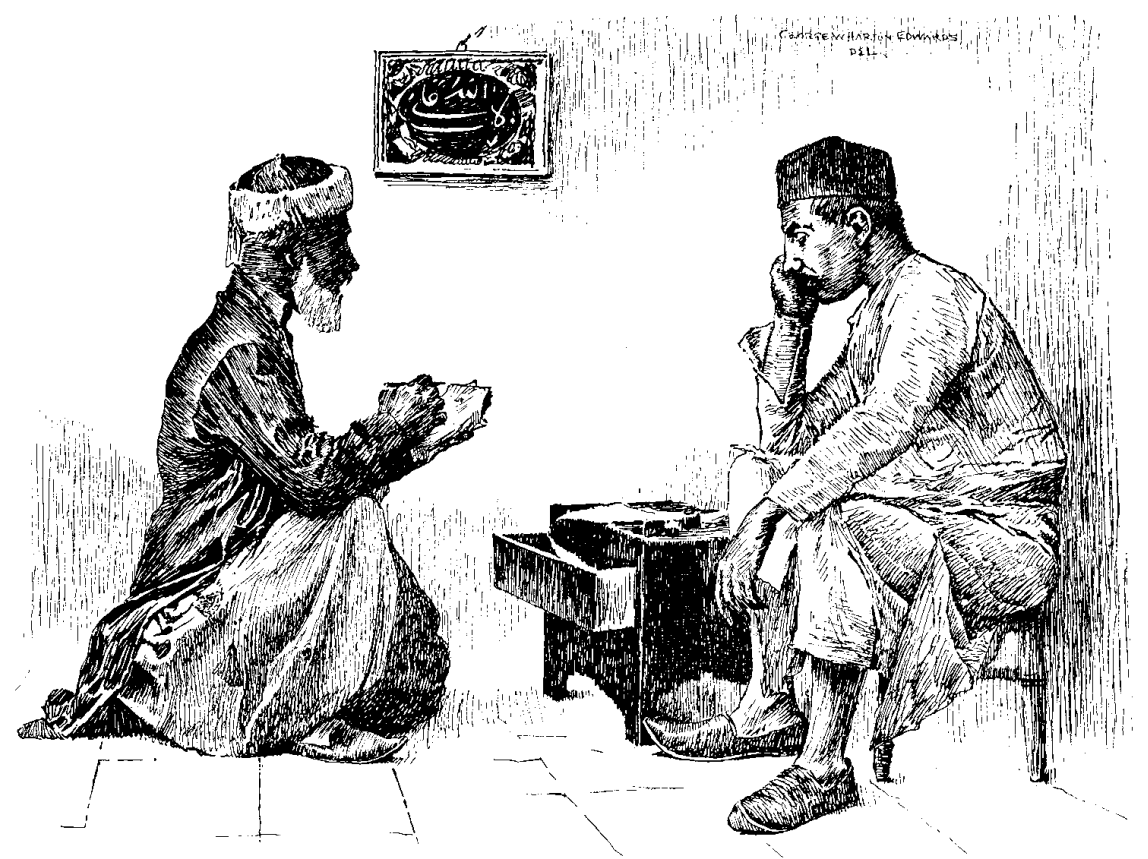


(en el sentido moderno -renacentista e ilustrado) la vida. Con Virno el problema actual sería otro. En el presente ya no habría oposición entre acción comunicativa y acción instrumental, como lo denunciaba Habermas, pues en el proceso productivo mismo se habría instalado la palabra: el trabajo se convirtió en interacción social (Santos, 2008). Se ha roto el silencio que se requería en la forma trabajo durante el capitalismo industrial y en la sociedad disciplinar.

En la sociedad posfordista, se sigue dependiendo de la medida del tiempo de trabajo, pero ésta ha sometido los tiempos del lenguaje al trabajo y lo ha capturado, o por lo menos lo intenta someter. El lenguaje es hoy el terreno del conflicto y lo que está en juego política y económicamente hablando. Con Hardt y Negri (2002), Virno plantea que el trabajo contemporáneo tiene un carácter lingüístico y cognitivo, pero incluyendo en el lenguaje el cuerpo y la vida toda: placer, dolor, pasión. Esto ha sucedido durante toda la historia de la humanidad, pero ahora aparece como objeto de disputa entre las luchas globalizadas de resistencia y el capitalismo posfordista. Este intento por controlar la vida, así entendida (lenguaje+trabajo) no es connatural a todas las formas de producción, sino propio del capitalismo contemporáneo. De allí surge un concepto como el de biopolítica, del que se ocupa un número importante de teóricos posestructuralistas (Deleuze, 2007, Foucault, 2007, Heller, 1995 y Lazzarato, 2006a y 2006b).

El trabajo en el capitalismo ya no supone el silencio durante el proceso de producción, ni la segmentación y la especialización en el proceso productivo. Al contrario requiere las capacidades lingüísticocomunicativas, la creatividad y el intercambio original de ideas. La segmentación se da, pero explícitamente es flexible, reversible y móvil. Sin embargo, tal comunicación lingüística no deviene en esfera pública, al contrario, puede devenir en una dependencia jerárquica más absorbente que en la producción industrial. Ya no se depende de unas reglas de sujeción anónimas, sino de una persona, y la dependencia no ad- ministra unas horas de trabajo y unas funciones específicas, sino a la persona del trabajador toda, en su condición más humana, esto es: la comunicación y el intelecto. En ese sentido, es al intelecto general (comunicación e intelecto) ${ }^{6}$ al que se le administra; es la multitud sujetada (Hardt, 2004).

La clase obrera no desaparece. La clase obrera es, según Marx, una categoría abstracta que hace alusión al trabajo que produce un plusvalor, a través del trabajo vivo-subordinado, cuyo rasgo fundamental es el general intellect (intelecto general) por su capacidad linguística. Esa clase sigue existiendo en el capitalismo posfordista, por supuesto, pero ya no en la forma-Estado. Ya no tiene una vocación popular-estatal, ya no deviene pueblo (entendido como clase trabajadora). La multitud sigue produciendo plusvalor, pero las formas organizativas que conducen las causas que defienden o controlan a esa multitud cambian, con lo cual cambian las mentalidades y las modalidades mismas del conflicto. El posfordismo, pues, tiene su matriz fundante en la industria cultural, en la cual la producción se hace a través de los medios de comunicación.

Con la industria cultural el virtuosismo se masifica. En ella, la estructura del trabajo asalariado coincide con la acción política, porque como el trabajador no produce objetos, no se puede medir su eficiencia; como su producto es virtuoso, está basado en actos lingüísticos, entonces no se puede saber cuánta productividad genera. La multitud posfordista la conforman trabajadores virtuosos que acuden a cualidades basadas en las facultades genéricas del lenguaje y la comunicación y, en ese sentido, a cualidades políticas.

Guy Debord (1967, citado en Virno 2003) decía en La sociedad del espectáculo que espectáculo es la comunicación

6 El general intellect de Marx pasaría a ser otra cosa, pues ya no se expresaría en las máquinas, físicamente hablando, sino en la vida de las personas mismas, de todas, y no sólo de los trabajadores.

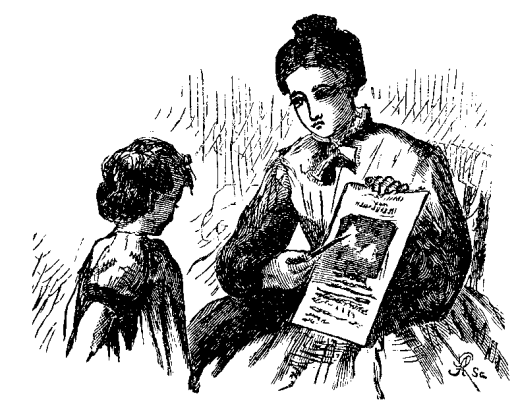

humana transformada en mercancía. La mercancía allí es la facultad de comunicarse, es un acto verbal. El asunto que nos interesa hoy no es tanto eso, ese no sería el problema, como se creía y se denunciaba antes, con algo de nostalgia por el arte puro, sino la manera en que esa mercancía se convirtió en un asunto que le interesa a todos los sectores industriales. El problema no es la industria cultural, sino que la acción comunicativa se convirtió en parte central de la estrategia productiva hoy: la cooperación productiva. La acción comunicativa, en tanto cooperación productiva, es una fuerza productiva determinante hoy. Competencias lingüísticas, saber, comunicación, creatividad, eso es lo que se necesita hoy en todo proceso laboral para competir con éxito. $Y$ estas cualidades se muestran "fetichizadas" (porque se separan del proceso productivo mismo) en el mundo del espectáculo. Además de ser parte de la industria cultural, el espectáculo es la fuerza productiva que determina hoy el modo de producción capitalista. (para Debord es la exposición general de la racionalidad del sistema). Lo que se pone en escena son las fuerzas productivas mismas, pues las competencias lingüístico-comunicativas, el general intellect, son las que regulan la producción hoy.

Igual que el dinero, el espectáculo es una mercancía, es algo concreto, pero a la vez es la unidad de medida del intercambio de las demás mercancías, y allí encuentra su naturaleza abstracta, universal; con una diferencia, y es que el dinero mide lo que la sociedad ya hizo, los productos ya producidos, pero el espectáculo muestra las capacidades, las potencialidades que la sociedad tiene, lo que puede ser y hacer, y en este caso 
esa potencia radica en la cooperación productiva (Blondeau et al., 2004). De esa manera, el espectáculo, la industria cultural o de la comunicación no es sólo un sector industrial, sino la industria de los medios de producción, el lugar donde se generan los medios de producción.

La industria de los medios de producción es, por lo general, el lugar donde se producen las máquinas que luego se utilizan en los más variados procesos industriales de producción de bienes de consumo, pero hoy ya no solo son máquinas. Los medios de producción son competencias linguísticas-cognitivas, propias del trabajo vivo. Esos medios de producción de hoy son técnicas y procedimientos comunicativos que se producen en la industria cultural (las escuelas, los colegios, los institutos técnicos y la universidad hoy serían parte de ese sector llamado industria cultural). Allí se innova y se experimenta para producir aquellos bienes que luego se utilizarán en los demás sectores de la economía. La actividad sin obra se convirtió hoy en el prototipo del trabajo asalariado (aunque se sigan produciendo bienes materiales, por supuesto).

\section{LAS IMPLICACIONES PARA LA EDUCACIÓN}

¿Cómo inciden en las instituciones educativas estos cambios en el modo de producción? Esta es una pregunta que debemos responder mediante un trabajo serio y riguroso de más largo aliento. $Y$ a ésta se suman otras: ¿Qué es lo que pueden hacer la escuela y la universidad hoy? ¿Cuáles son sus relaciones con el Estado, con la sociedad, con la infancia, con la juventud, con el mundo del trabajo, con la cultura, frente al capitalismo, frente al pasado, al presente, al futuro? Indagar sobre estas relaciones es fundamental para que los profesores podamos aportar a las decisiones que se están tomando acerca del presente y el futuro de la educación básica, media y superior y ayudar a los jóvenes a entender su lugar en el mundo de hoy. Veamos algunas pistas para acercarnos a esta problemática.
Volviendo a Lyotard (1987), los cambios en el modo de producción de bienes, regulados por la performactividad (eficiencia), han afectado la enseñanza. Según este autor, el conocimiento está regido por criterios como la normalización, la miniaturización y su comercialización; esto modifica necesariamente su adquisición, su clasificación y el acceso a la información y a su explotación. El saber entonces se transforma, pues para poder ser producido y difundido, debe poder ser cuantificado en bits; lo que no pasa por el formato de los lenguajes telemáticos ya no será conocimiento importante y, por tanto, pierde su legitimidad. Los resultados de las investigaciones también deben ser traducibles al lenguaje de las máquinas. Quien inventa y quien aprende deben estar en condiciones de acceder y de traducir a ese lenguaje. Allí hay una lógica y unas prescripciones que determinan la aceptabilidad de los enunciados. Ya la vieja idea de que el saber era importante, en tanto que formaba a la persona, ha entrado en desuso. La relación de los productores y los aprendices de conocimiento está conectada con el saber, de la misma manera que los productores de bienes y sus consumidores se relacionan con las mercancías, esto es, produciendo valor.

Si se entiende a la universidad como un subsistema del sistema social, y si la sociedad se performatizó, entonces ella debería actuar en función de esta sociedad, con arreglo a una lógica preformativa. ¿Esto es lo que se entiende cuando decimos que la educación debe responder a la sociedad, o estar de cara a la sociedad? Según las exigencias del capitalismo contemporáneo, la escuela y la universidad deberían cumplir dos funciones fundamentales:

1. Ser competitivas a nivel mundial. Esto significa, en su lógica, que debemos formar los cuadros y los expertos en las áreas de punta del conocimiento: informáticas, cibernéticas, lingüísticas, matemáticas.

2. Mantener la cohesión social. Ya no a partir del principio de la emancipación, o a partir de ideas, sino a partir de competencias, esto es: tantos técnicos, tantos médicos, tantos ingenieros (profesionalizar). Ya no se trata de formar una élite que guíe la nación, sino jugadores que sepan manejar la pragmática para hacer progresar las empresas.

Para que esto pueda ser posible, la educación debería ser capaz de garantizar la formación permanente, pues la velocidad de los cambios hoy exigiría un reciclaje continuo. En esas alternativas educativas, el saber no sería transmitido en bloque, completo, sino "a la carta", y sus destinatarios no serían jóvenes futuros trabajadores, sino trabajadores que buscan mejorar o actualizar sus competencias para promocionarse y ser competentes con la información, en el uso de lenguajes, para desempeñarse con éxito en los nuevos juegos del lenguaje. Estos programas funcionarían en instituciones dispuestas a ofrecer todas las enseñanzas que la sociedad esté dispuesta a pagar. Con esto, se estaría creando un basto mercado de competencias operacionales (ver ofertas de diplomados y cursos de las universidades en la prensa dominical).

Para esto último, la institución educativa, en su autonomía, suele ser muy pesada, tradicional y conflictiva, por eso tiende a dejársele a instituciones que comienzan a constituirse por fuera del sistema público (educación privada, con subsidio o en concesión), lejos del mundo de los ilustrados y de los estudiantes que siguen creyendo en el saber por el saber, con un fin en sí mismo, como realización de la idea o para la emancipación de la humanidad.

Los currículos contemporáneos deberían garantizar la utilización de las nuevas tecnologías de la información, porque ellas permiten soportar las lógicas comunicacionales por las cuales circula eficientemente el conocimiento que se necesita. Tales conocimientos tendrían que ser todos traducibles a lenguajes informáticos, que es donde se guarda la memoria actual. Su acceso (la nueva didáctica) se hace mediante bancos de datos de terminales inteligentes. 
Lo que hoy hay que enseñar, entonces, es manejar esos terminales y los nuevos lenguajes (informática, telemática y una lengua extranjera...) y a formular las nuevas preguntas. La pregunta a la que se busca que responda la búsqueda del conocimiento ya no es ¿eso es verdad?, sino ¿eso para qué sirve? En el contexto de mercantilización del saber la pregunta es: ¿se puede vender? Y en el contexto de la argumentación del poder: ¿es eficaz?

A propósito de la volatilidad del saber contemporáneo, Zigmunt Bauman (2002) nos recuerda que educar ya no es fijar en una forma, como lo fue en la ilustración, para lo cual se fundaron las instituciones como la escuela y la universidad. Si lo que es deseable hoy es desprenderse de las cosas para darle lugar a las nuevas, si ya no es un valor guardar nada, producir algo para que perdure, para que permanezca, si educar ya no es para toda la vida, sino que hay que aprender a aprender, entonces la pedagogía debería preocuparse hoy por enseñar a utilizar los conocimientos aquí y ahora, y para estar dispuesto a olvidar pronto, a desechar lo aprendido, a desaprender, nos dice el autor.

¿Tiene sentido hablar hoy de ofrecer una educación sólida y estructurada, rigurosa y profunda, que sirva para toda la vida? Estas serían palabras pesadas, que no permitirían moverse rápidamente y que no nos ayudarían a estar prestos al cambio. Por eso, no es fácil convencer hoy a los jóvenes para que permanezcan en la escuela o en la universidad. La ilusión que los padres tenían antes de trabajar duro para poder darles a los hijos lo más preciado: la educación, porque eso perduraba, porque eso no se gastaba y darles así unas buenas bases con las cuales podrían defenderse toda la vida, ya no le da risa a los jóvenes, sino que los espanta: hoy dirían, por favor no me des nada que me pese, que me toque cargar toda la vida, que me dure siempre. Eso no me dejaría mutar para adecuarme con rapidez a los cambios". La escuela pesa. Por eso habría que acortar las carreras, flexibilizarlas, por eso habría que reformar el currículo, para ponerlo a funcionar en un nuevo paradigma según el cual los estudiantes pueden armar a su gusto, modularmente, los contenidos; con esto podrían hacer recorridos inesperados, según se vayan presentando las oportunidades y las necesidades; este sería un currículo abierto, no secuencial, que rompe la lógica lineal, que no tiene objetivos a largo plazo.

Una formación para la estabilidad suponía que el conocimiento reflejaba el mundo. Esto bajo el supuesto de que el mundo era estático y como tal permanecía en el tiempo, dado que obedecía a leyes naturales que eran inmutables y universales. En ese caso, se trataba de descifrarlas, y de eso se ocuparía la investigación, de ir aproximándose cada vez más a una idea cierta de esas leyes. En ese caso, el conocimiento podía cambiar, podía cambiar la mirada sobre él, o la idea que tuviéramos de él.

Pero, ¿cuando el mundo es el que cambia? ¿Qué le pasa al conocimiento? y ¿qué le pasa a las instituciones que se hicieron para administrar ese conocimiento? ¿Cómo conocer algo que muta permanentemente?

Lo que produce vértigo es que el conocimiento científico dejó de creer que podía reflejar el mundo hace cien años, con la teoría de los Cuantas. Es increíble cuánto ha resistido la escuela y la universidad. Hay algo en esas instituciones que todavía nos resistimos a olvidar, porque si no, ya hubieran desaparecido, tal como se predijo en varias ocasiones. Pero, ¿qué es lo que las hace permanecer? ¿Cómo la sociedad todavía soporta la enseñanza y la pedagogía? En ese misterio debe haber algo potente, desde lo cual quizás podemos entender lo que somos como docentes. Tal vez lo que ha muerto es la pretensión de verdad, como vimos arriba con Lyotard. Pero, ¿habrá algo de los viejos ideales de la paideia griega que heredó la pedagogía, relacionado con lo justo, lo bello y lo bueno, que todavía se resista a desaparecer?, ¿serán las escuelas y las universidades el último bastión de aquellos principios?, ¿es este un ideal romántico, conservador, obsoleto y utópico?
Las instituciones educativas han sido intervenidas y ya son otra cosa en el capitalismo cognitivo. Los rectores son gerentes, los profesores son acompañantes, los estudiantes son diversos y tienen derecho al desarrollo de su libre personalidad, los conocimientos son volátiles y provisionales, existen en un nuevo formato llamado competencias que se pueden medir universalmente por medio de su estandarización. Las instituciones educativas hoy son inteligentes, porque tienen la habilidad de cambiar de acuerdo con las necesidades de la sociedad (¿del mercado?), de los nuevos valores que se transforman de manera permanente.

Reivindicar ahora la novedad, la irrupción de lo nuevo en la producción de conocimiento no sería sólo un principio de los valores que había fundado a la universidad, cuando se había instituido como el lugar para el pensamiento creativo y crítico, donde la diferencia tendría su trinchera, ahora sería un principio también demandado por el mercado. En este juego de posibilidades, lo que se nos plantea es un gran reto para saber hacia dónde dirigir nuestros proyectos intelectuales, sin renunciar a la invención de mundos posibles.

El desafío que se les plantea a las instituciones educativas es dos veces más complejo que el que se le plantea al conocimiento, porque éste debe ser capaz de moverse de acuerdo con la velocidad de los cambios sociales, y la escuela y la universidad deben enseñar a aprender cómo moverse. Si el asunto es político y estamos en el juego, podemos discutir hacia dónde.

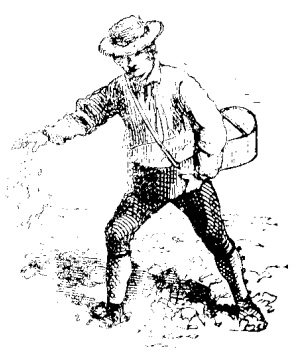




\section{BIBLIOGRAFÍA}

BACHELARD, G. (1948). La formación del espíritu científico. México: Siglo XXI Editores.

BAUman, Z. (2007). Desafíos pedagógicos y modernidad líquida. Revista Propuesta Educativa, año 16, pp. 3-18.

Blondeau, O. et al. (2004). Capitalismo cognitivo, propiedad intelectual y creación colectiva. Madrid: Traficantes de Sueños.

Bonvecchio, C. (edit.). (1991). El mito de la universidad. México: Siglo XXI Editores.

Balibar, E. (1977). De Bachelard a Althusser: el concepto de "corte epistemológico". En La filosofía y las revoluciones científicas (pp. 9-47). México: Grijalbo.

Deleuze, G. (2007). Dos regímenes de locos. Textos y entrevistas (1975-1995). Valencia: Pre-Textos.

DıAZ, M. et al. (2006). Educación superior: horizontes y valoraciones. Relación PEI-ECAES. Cali: Icfes-Universidad de San Buenaventura.

FREY, H. (1991). Las raíces de la modernidad en la Edad Media. Revista Mexicana de Sociología, A4. pp. 3-44

Foucault, M. (1970). La arqueología del saber. México: Siglo XXI Editores.
Foucault, M. (2007). Nacimiento de la biopolítica. Buenos Aires: Fondo de Cultura Económica.

Hardt, M., y Negri, A. (2002). Imperio. Buenos Aires: Paidós.

Hardt, M., y Negri, A. (2004). Multitud. Guerra y democracia en la era del Imperio. Barcelona: Debate.

Heller, A. y Ferenc, F. (1995). Biopolítica. La modernidad y la liberación del cuerpo. Barcelona: Península.

KoYRÉ, A. (1977). Estudios de historia del pensamiento científico. México: Siglo XXI Editores.

Lazzarato, M. (2006a). Políticas del acontecimiento. Buenos Aires: Tinta Limón.

Lazzarato, M. (2006b). Por una política menor. Acontecimiento y política en las sociedades de control. Madrid: Traficantes de sueños.

LYOTARD, J. (1987). La condición posmoderna. Madrid: Cátedra.

Lucio, R. y SerRano, M. (1992). La educación superior. Tendencias y políticas estatales. Bogotá: Universidad Nacional de Colombia. Instituto de Estudios Políticos y Relaciones Internacionales.
Ministerio de Educación SuperioR-ICFes. (2001). Bases para una política de estado en materia de educación superior. Bogotá: Icfes.

Organización de Estados IberoameriCANOS. (1999). Universidad siglo XXI. Revista Iberoamericana de Educación, 21.

Santos Calderón, G. (2008, abril 28). Nueva inteligencia. El Tiempo. p. 2

UnIVERSIA. (2005). Primer encuentro Internacional de Rectores de Universia. La Universidad Iberoamericana en la Sociedad del Conocimiento. Universidad de Sevilla 19 y 20 de mayo.

VIRNo, P. (2003). Gramática de la multitud. Madrid: Traficantes de Sueños.

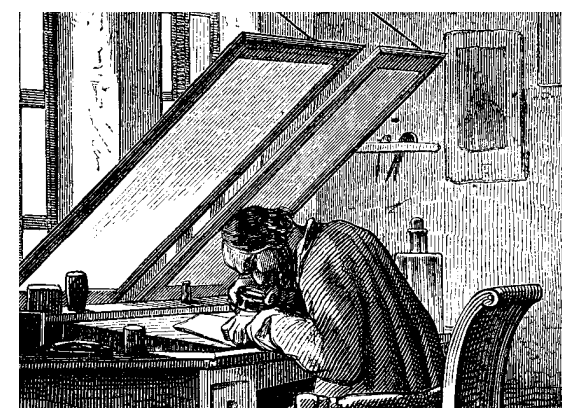

